\title{
Intraparotid Facial Nerve Schwannoma: A Report of Two Cases
}

\author{
Muhammet Fatih Topuz ${ }^{1}$, Ömer Genç², Nilufer Kadioglư ${ }^{3}$, Üstün Osma ${ }^{4}$
}

\begin{abstract}
Schwannoma is a benign, asymptomatic, solitary, and encapsulated tumor that grows slowly from peripheral, autonomic, or cranial nerve sheaths. The origin of the schwannomas in the facial nerve is rare and they tend to occur in the intratemporal part of the nerve. An intraparotid facial nerve schwannoma is usually a painless, slow-growing mass like the other benign parotid tumors. In this case report, we will discuss the clinical presentation, management, and outcome of two patients with intraparotid facial nerve schwannoma.
\end{abstract}

Keywords: Facial nerve, Parotid gland, Schwannoma.

Otorhinolaryngology Clinics: An International Journal (2020): 10.5005/jp-journals-10003-1343

\section{INTRODUCTION}

Most of the parotid masses are benign neoplasms (80\%). Pleomorphic adenoma, Warthin tumor, oncocytoma, monomorphic adenoma, and benign lymphoepithelial lesions are the most common tumors. ${ }^{1}$ The incidence of parotid tumors originating from the facial nerve is $0.2-1 \% .^{2}$ Schwannoma is a benign, asymptomatic, solitary, and encapsulated tumor that grows slowly from peripheral, autonomic, or cranial nerve sheaths. Schwannomas are mostly seen in the head and neck region (25-40\%) or on the flexor face of the extremities. ${ }^{1}$ They may originate from other nerves in the parapharyngeal region, most commonly from the vagus nerve. The origin of the schwannomas in the facial nerve is rare and they tend to occur in the intratemporal part of the nerve.

Since the extratemporal facial nerve schwannomas (FNSs) or neurofibromas are quite rare neurological lesions, preoperative diagnosis is very difficult. The misdiagnosis and mismanagement of the extratemporal FNS would lead to the drastic consequences of facial nerve injuries. Thus, it is important to know the diagnosis and management methods to be performed when facial nerve tumors are suspected. The present case study aims to consider the clinical presentation, management, and outcome of two patients with schwannomas of the facial nerve involving the intraparotid area.

\section{Case Descriptions}

\section{Case 1}

A 55-year-old male patient was admitted to our clinic for approximately 18 months because of a painless and slowly growing swelling in front of his left ear. On physical examination, there was a relatively mobile, hard, and painless mass in the left parotid region, $3 \times 4 \mathrm{~cm}$ in size. Facial nerve functions and other otolaryngologic examinations were normal. Hematological and biochemical tests were normal.

Parotid ultrasonography (USG) revealed a lesion of the size $34 \times 48 \mathrm{~mm}$ on hypoechoic, lobule, and necrotic areas in the posterior part of the left parotid gland and lymph nodes $9 \mathrm{~mm}$ in diameter on the left preauricular area. Magnetic resonance imaging (MRI) revealed a massive lesion on the left parotid gland, predominantly in the deep lobe and extending in the superficial lobe, with a size of approximately $3.5 \times 2 \times 4.5 \mathrm{~cm}$, with common cystic areas and nodular formations. The lesion was localized in a position consistent with the facial nerve entrapment in the supraordinarily mastoid bone level. Thus, the lesions arising from the
1,2Department of Otorhinolaryngology, Kütahya Sağlık Bilimleri University Faculty of Medicine, Evliya Celebi Education and Research Hospital, Central Kutahya, Turkey

${ }^{3}$ Department of Pathology, Kütahya Sağlık Bilimleri University Faculty of Medicine, Evliya Celebi Education and Research Hospital, Central Kutahya,Turkey

${ }^{4}$ Department of Otorhinolaryngology, Akdeniz University Faculty of Medicine, Central Antalya, Turkey

Corresponding Author: Muhammet Fatih Topuz, Department of Otorhinolaryngology, Kütahya Sağlık Bilimleri University Faculty of Medicine, Evliya Celebi Education and Research Hospital, Central Kutahya, Turkey, Phone: +90 5532668855, e-mail: drfatihtopuz@yahoo.com

How to cite this article: Topuz MF, Genç O, Kadioglu N, et al. Intraparotid Facial Nerve Schwannoma: A Report of Two Cases. Int J Otorhinolaryngol Clin 2020;12(1):4-7.

Source of support: Nil

Conflict of interest: None

facial nerve were primarily considered. When fine-needle aspiration biopsy (FNAB) was performed, the findings showed that there was a fibroid cell mesenchymal tumor and that cytomorphological findings were primarily suggestive of cellular-type schwannomas.

The patient underwent an operation with left-modified Blair parotid incision under general anesthesia with the preliminary diagnosis of FNS. It was observed that the mass was in a size of about 30 $\times 40 \mathrm{~mm}$ with a multilobule appearance. The facial nerve was identified approximately $1 \mathrm{~cm}$ distal to stylomastoid foramen. The tumor was dissected by preserving the thin branches of the facial nerve.

On the facial nerve examination performed postoperatively, House-Brackman grade V facial paralysis was present. On the histopathological examination, the tumor showed short bundles. Palatine was observed around the fibrillary material. There were cellular areas formed by spindle cells with eosinophilic cytoplasm whose borders were not clearly defined. In some areas, it has been reported that the lesion appeared to occur from less cellular areas that consisted of spindle-oval nucleated cells with a welldeveloped distribution in the loose matrix. In the established immunohistochemical study, the lesion-forming cells were stained with $\mathrm{S} 100$. The diagnosis was reported as schwannoma. After approximately 1 month of follow-up, the patient's facial nerve and eye movements were observed to be slightly paralyzed. 


\section{CASE 2}

A 65-year-old male patient was admitted to our clinic for a painless and growing swelling in front of the left ear bucket for approximately 4 years. Physical examination revealed a mass of $3 \times 4 \mathrm{~cm}$, oval, relatively mobile, hard, and painless covered by normal skin in the left parotid region. The facial nerve functions were normal. The patient denied otalgia, fever, weight loss, or night sweats. Other otolaryngologic examinations were normal.

Ultrasonographic examination revealed a hypoechoic mass of $30 \times 25 \mathrm{~mm}$ located in the left parotid gland. Magnetic resonance imaging showed intraparotid lesion as a mass with an intense signal to muscle on $\mathrm{T} 1$ and hyperintense signal to muscle on $\mathrm{T} 2$ sequence approximately $28 \times 27 \times 30 \mathrm{~mm}$ in the lateral segment of the superficial lobe on the left parotid gland (Figs 1 and 2).

The patient underwent an operation with left-modified Blair parotitis incision under general anesthesia. The facial nerve was identified approximately $1 \mathrm{~cm}$ distal to stylomastoid foramen. It was observed that the mass was in a size of about $20 \times 30 \mathrm{~mm}$ located

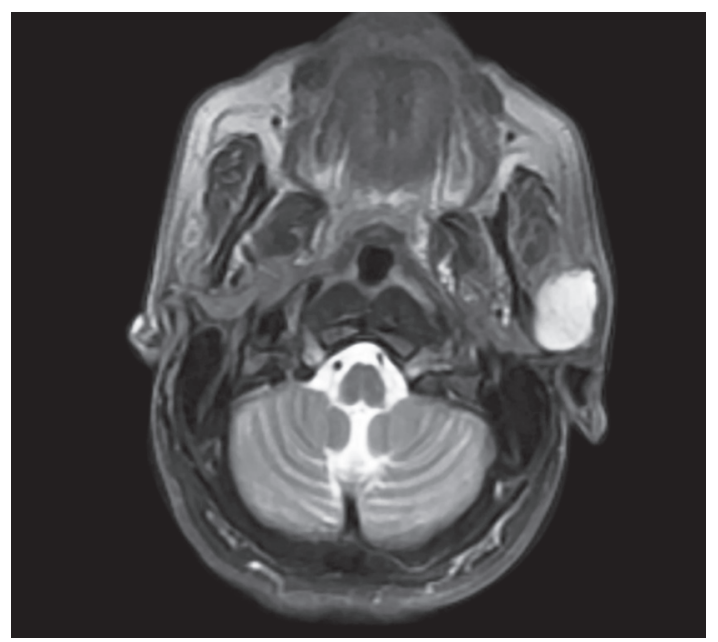

Fig. 1: An intense signal to muscle on $\mathrm{T} 1$ and hyperintense signal to muscle on T2 sequence approximately $28 \times 27 \times 30 \mathrm{~mm}$ in the lateral segment of the superficial lobe on the left parotid gland

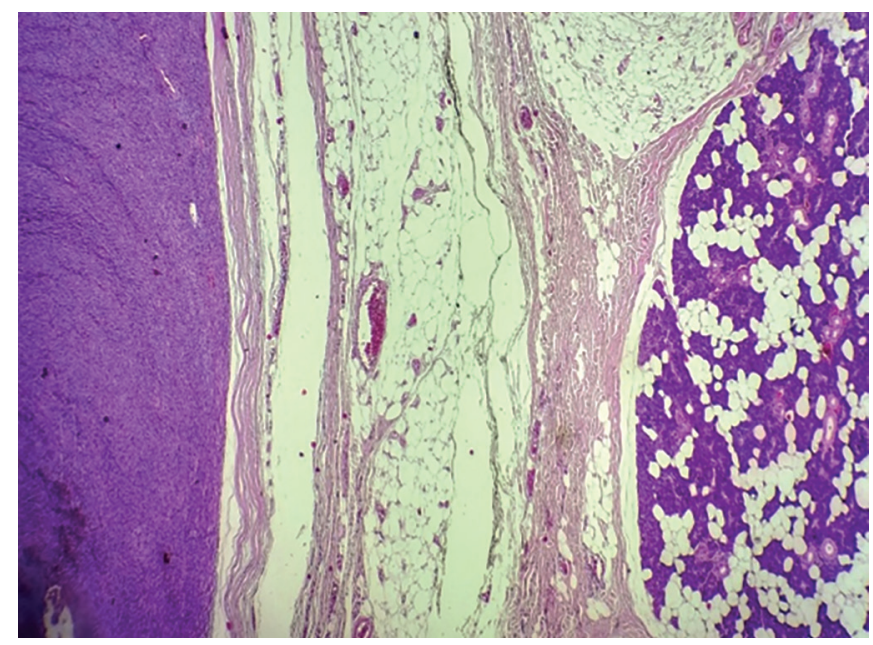

Fig. 3: On the left side there is the normal appearance of salivary gland, and on the right side there is an encapsulated lesion composed of spindle cells $(\times 4 \mathrm{HE})$ in the temporozygomatic branch of the facial nerve. It was seen that the tumor surrounded the temporozygomatic branch of the facial nerve at the superior part of the temporomandibular joint. The mass was removed along with the facial nerve. Postoperative follow-up showed a limitation in forehead muscle movements. Left eyelid movements were intact.

Histopathologic examination revealed a capillary, well-limited tumor formation with minimal pleomorphism that consisted of spindal cells or round cells in the hypercellular palisading pattern. Immunohistochemical staining revealed that tumor cells were positively stained with vimentin, S100, and CD10. Pancytokeratin (PANC), smooth muscle antigen (SMA), and glial fibrillary acidic protein (GFAP) were observed to give a negative reaction. The Ki 67 proliferative index was low. Despite that GRAF was negative, other histologic and immunohistochemical findings were described as "cellular schwannoma" (Figs 3 to 6). In approximately 1 month after the patient's check-up, left forehead movements were observed to be slightly paralytic.

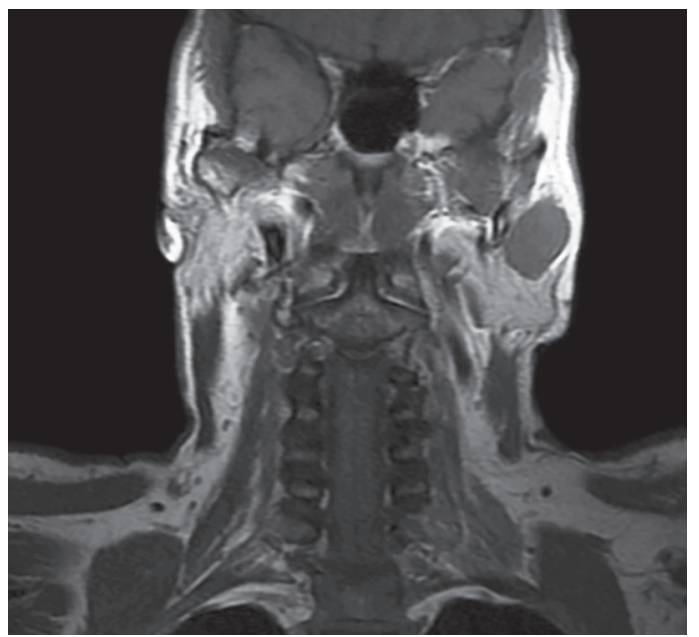

Fig. 2: An intense signal to muscle on $\mathrm{T} 1$ and hyperintense signal to muscle on T2 sequence approximately $28 \times 27 \times 30 \mathrm{~mm}$ in the lateral segment of the superficial lobe on the left parotid gland

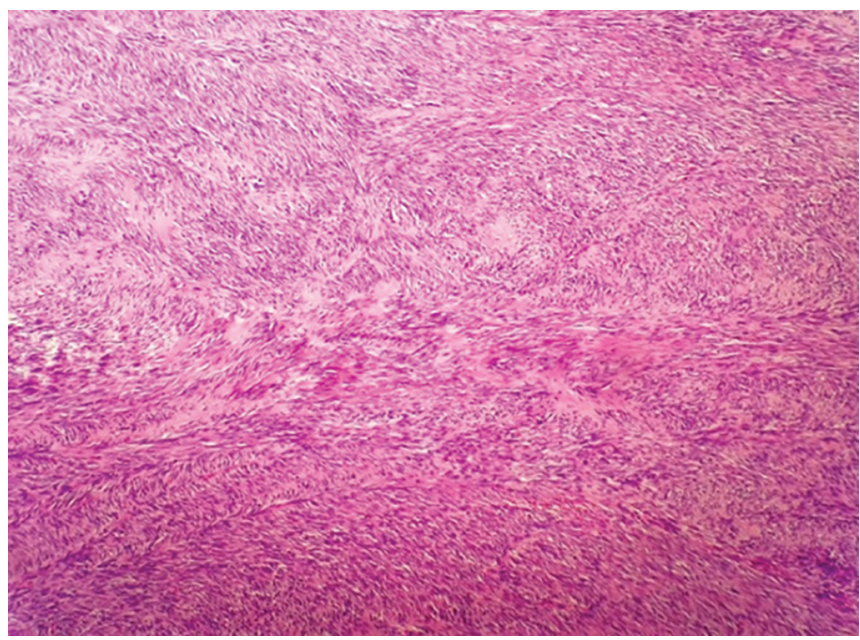

Fig. 4: A palisading biphasic spindle cell tumor containing hypercellular (Antoni A) and hypocellular (Antoni B) areas ( $\times 10 \mathrm{HE})$ 


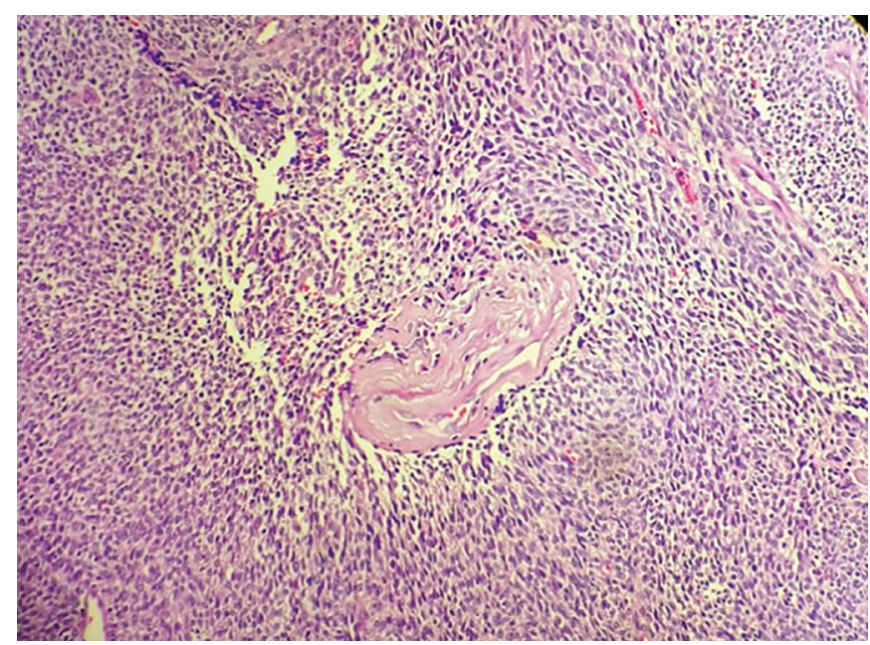

Fig. 5: Hyalinized wall vascular structures distributed between spindle tumor cells $(\times 20 \mathrm{HE})$

\section{Discussion}

Schwannoma (neurilemmoma) was first described by Stout in 1935. Schwannomas are known to originate from the neuroectodermal sheath of the peripheral nerve. ${ }^{1}$ The etiological factor of the schwannoma is unknown. They are most commonly seen between third and fourth decades. The relevant literature indicates that the ratio of men to women varies between 1:1, 3:2 or 2:1. ${ }^{2}$ Facial nerve schwannomas (i.e., neurilemmomas, neurinomas) are rare, slowgrowing neoplasms that may originate from the cerebellopontine to the peripheral branches of the facial nerve. Most of the FNSs are intratemporal with $9 \%$ occur in the parotid region. ${ }^{3}$

Intraparotid FNSs are usually painless, slow-growing, and quite rare benign parotid tumors. The reported number of FNSs in the literature is approximately 400, and slightly more than 70 is intraparotid. ${ }^{4}$ Facial nerve dysfunction is detected in only $20 \%$ of cases. ${ }^{1-5}$ Erbek et al. published a case of intraparotid FNS who underwent pain with facial paralysis. ${ }^{6}$

Preoperative diagnosis is very difficult, because the FNS is a very rare neurological lesion. Bretlau et al. reported that the preoperative diagnosis of only 4 patients was correct in their series of 52 patients. ${ }^{7}$ Caughey et al. found out that the schwannoma masses were symptomatic at an average of 8.4 years, whereas the intraparotid FNS lasted longer than 10 years. ${ }^{5}$ However, it is notable that the prolonged duration of symptoms does not mean schwannoma.

There is no evidence that any radiological method is of particular assistance. Ultrasound examination has similar findings in pleomorphic adenoma with FNS. ${ }^{8}$ Computed tomography scan is done for usually smooth and sharply circumscribed lesion in the parotid, which is difficult to differentiate from other tumors. ${ }^{9}$ However, even small FNS lesions in the MRI facial nerve tract could be distinguished. ${ }^{9}$ Magnetic resonance imaging shows intraparotid FNS T1 as an isointense signal and T2 as a hyperintense signal. Similar MRI images were obtained in both of our cases.

The results of FNAB are not often descriptive. It is usually reported as a myxoid material or a number of stem cells that are inadequate for cytological diagnosis. ${ }^{10}$ In the first case, FNAB was reported to be a pathological endothelial cell mesenchymal tumor and primarily a cellular schwannoma. In our second case, it was reported as an insufficient material.

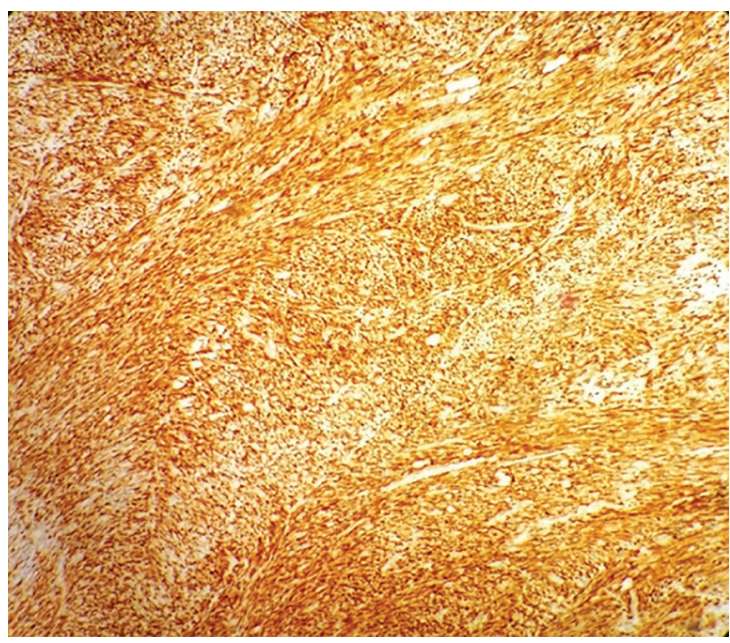

Fig. 6: The Tumor cells were stained with S100 $(\times 10)$

Schwannoma can be microscopically seen in two diverse histological patterns. 'The Antoni type A cytoplasm is evident, the nuclei are palisaded, and the elongated spindle cells are visible. ${ }^{1}$ This view is defined as Verocay bodies. In Antoni B, there are scattered nuclei with a hypocellular structure. ${ }^{10}$ Pleomorphic cells are observed in the loose stroma. Both types may be present in the same specimen. Schwannomas may exhibit areas of cystic degeneration with local necrosis. Malignant degeneration is rare. ${ }^{1}$ The presence of Antoni $A$ and Antoni B cell patterns on histopathological sections and the presence of S100 and vimentin $(+)$ in the immunohistochemical examination revealed schwannoma. ${ }^{11}$

When FNS is macroscopically examined, it is yellow and rubbery. Thus, other salivary glands cannot be distinguished from benign tumors. ${ }^{5}$ The most diagnostic feature of intraparotid FNS is intraoperative difficulty in locating the facial nerve. ${ }^{10}$ The frozen section that could be delivered during surgery can help in the diagnosis. ${ }^{10}$ However, it may bring about facial nerve paralysis. ${ }^{10}$

Patients should be adequately informed about treatment options when planning FNS therapy, and the treatment should be decided by the physician and the patient, with consideration of facial nerve functions. Intraparotid FNS therapy is observation, decompression, or total excision of the tumor. ${ }^{2}$ If the observation option is preferred, it may be followed up closely with serial electroneurography and CT. However, in our opinion, observation protocols should be reserved for older patients and patients with a serious comorbid systemic disease.

According to Prasad et al., it was determined that the main trunk of the facial nerve was most frequently involved in intraparotid FNS cases. ${ }^{1}$ They reported that total tumor removal with nerve preservation was performed in only five cases. ${ }^{1}$ In our first case, the tumor was in the main trunk of the facial nerve. In our second case, the tumor was localized in the temporozygomatic branch of the facial nerve. However, because of the multicentric tumor possibility, intraoperative examination of the main truncus and all peripheral branches of the facial nerve is recommended. ${ }^{12}$

Facial nerve schwannomas are solitary, encapsulated, and usually sinusoidal tumors. The sinus is seen as pushing to one side, and with the preservation of the nerve, it may allow surgical removal 
of the tumor. ${ }^{1-13}$ For the preservation of the facial nerve, the tumor could be enucleated by preserving the capsule of the nerve. Öncel et al. noted that in the superficial lobes, a schwannoma located between the temporal and zygomatic branches of the facial nerve was removed by superficial parotidectomy without significant facial nerve damage. ${ }^{14}$ If the tumor is not totally excised, it may recur. ${ }^{2-6}$ In cases where complete excision cannot be performed, a second surgery may not be necessary because the tumor is growing too slowly. However, it may also be necessary to reexamine the recurrent tumor. ${ }^{2-5}$ In our first case, FNS was removed by enucleation. In our second case, the enucleation was not performed due to the considerable thinning of the facial branch, and the tumor was totally removed together with the nerve. There was no recurrence in both of our cases.

In cases where the nerve is interrupted, greater auricular or sural nerve could be used to maintain continuity. ${ }^{1}$ Segas et al. reported that in a patient with complete facial paralysis, they achieved excellent results after 2 years with hypoglossal-facial anastomosis in the postoperative 6 th month. ${ }^{2}$

\section{ConcLusion}

Although FNSs are rare in the parotid region, physicians should be careful. Since preoperative examinations cannot be diagnosed and could be confused with other parotid tumors, it should be kept in mind that the tumor may be FNS, particularly when the facial nerve cannot be distinguished easily from the tumor during removal of parotid masses.

\section{References}

1. Prasad S, Myers EN, Kamerer DB, et al. Neurilemmoma (schwannoma) of the facial nerve presenting as a parotid mass. Otolaryngol Head Neck Surg 1993;108(1):76-79. DOI: 10.1177/019459989310800111.
2. Segas JV, Kontrogiannis AD, Nomikos PN, et al. A Neurilemmoma of the parotid gland. Ent J 2001;60(7):468-470.

3. Forton GE, Moeneclaey LL, Offeciers FE. Facial nerve neuroma. Report of two cases including histological and radiological imaging studies. Eur Arch Otorhinolaryngol 1994;251(1):17-22. DOI: 10.1007/BF00175952.

4. Sahejmeet S, Guraya BS, Richard A, et al. Peripheral nerve sheath tumors arising in salivary glands: a clinicopathologic study. Annals of Diagnostic Pathology 2016;23:38-42. DOI: 10.1016/ j.anndiagpath.2016.06.001.

5. Caughey RJ, May M, Schaitkin BM. Intraparotid facial nerve schwannoma: diagnosis and management. Otolaryngol Head Neck Surg 2004;130:586-592. DOI: 10.1016/j.otohns.2003.12.011.

6. Erbek HS, Erbek SS, Tosun E, et al. Parotis içi yerleşimli fasiyal sinir schwannomu: Bir olgu sunumu. KBB ve BBC Dergisi 2005;13(1): 39-43.

7. Bretlau P, Melchiors $\mathrm{H}$, Krogdahl A. Intraparotid neurilemmoma. Acta Otolaryngol 1983;95(3-4):382-384.DOI: 10.3109/00016488309130957.

8. Gritzmann N, Rettenbacher T, Hollerweger A, et al. Sonography of the salivary glands. Eur Radiol 2003;13(5):964e975. DOI: 10.1007/ s00330-002-1586-9.

9. Jager L, Reiser M. CT and MR imaging of the normal and pathologic conditions of the facial nerve. Eur J Radiol 2001;40(2):133-146. DOI: 10.1016/S0720-048X(01)00381-3.

10. Bale $\mathrm{VH}$, Greisen $\mathrm{O}$. Neurilemmomas of the facial nerve presenting as parotid tumors. Ann Otol Rhinol Laryngol 1984;93(1 Pt 1):70-72. DOI: $10.1177 / 000348948409300116$.

11. Ma $Q$, Song $H$, Zhang $P$, et al. Diagnosis and management of intraparotid facial nerve schwannoma. Journal of Cranio-MaxilloFacial Surgery 2010;38:271-273. DOI: 10.1016/j.jcms.2009.07.005.

12. KızIl Y, Yılmaz M, Aydil U, et al. Facial schwannoma of the parotid gland in a child. Kulak burun boğaz ıhtis Derg 2008;18(3):175-178.

13. Chiang CW, Chang YL, Lou PJ. Multicentricity of intraparotid facial nerve schwannomas. Ann Otol Rhinol Laryngol 2001;110:871-874. DOI: $10.1177 / 000348940111000912$.

14. Öncel S, Önal K, Ermete M, et al. Schwannoma (Neurilemmoma) of the facial nerve presenting as a parotid mass. J Laryngol Otol 2002;116:642-643. DOI: 10.1258/00222150260171687. 